\title{
Organisational development in general practice: lessons from practice and professional development plans (PPDPs) Glyn Elwyn ${ }^{1}$ and Paul Hocking ${ }^{2}$
}

\author{
Address: ${ }^{1}$ Department of General Practice University of Wales College of Medicine Canolfan Iechyd Llanedeyrn Health Centre CF23 9PN. and \\ ${ }^{2}$ Primary Care Development Research Group NHS Staff College Wales Hensol Castle Pontyclun Mid Glamorgan CF72 8YS. \\ E-mail: Glyn Elwyn - elwyng@cardiff.ac.uk Paul Hocking - phocking@StaffCollegeWales.org.uk
}

Published: 19 December 2000

BMC Family Practice 2000, 1:2
Received: I 5 November 2000

Accepted: 19 December 2000

This article is available from: http://www.biomedcentral.com/I47I-2296/I/2

\begin{abstract}
Background: Improving the quality and effectiveness of clinical practice is becoming a key task within all health services. Primary medical care, as organised in the UK is composed of clinicians who work in independent partnerships (general practices) that collaborate with other health care professionals. Although many practices have successfully introduced innovations, there are no organisational development structures in place that support the evolution of primary medical care towards integrated care processes. Providing incentives for attendance at passive educational events and promoting 'teamwork' without first identifying organisational priorities are interventions that have proved to be ineffective at changing clinical processes. A practice and professional development plan feasibility study was evaluated in Wales and provided the experiential basis for a summary of the lessons learnt on how best to guide organisational development systems for primary medical care.
\end{abstract}

Results: Practice and professional development plans are hybrids produced by the combination of ideas from management (the applied behavioural science of organisational development) and education (self-directed adult learning theories) and, in conceptual terms, address the lack of effectiveness of passive educational strategies by making interventions relevant to identified system wide needs. In the intervention, each practice participated in a series of multidisciplinary workshops (minimum 4) where the process outcome was the production of a practice development plan and a set of personal portfolios, and the final outcome was a realised organisational change.

It was apparent during the project that organisational admission to a process of developmental planning needed to be a stepwise process, where initial interest can lead to a fuller understanding, which subsequently develops into motivation and ownership, sufficient to complete the exercise. The advantages of introducing expert external facilitation were clear: evaluations of internal group processes were possible, strategic issues could be raised and explored and financial probity ensured. These areas are much more difficult to examine when only internal stakeholders are engaged in a planning process.

Conclusions: It is not possible to introduce practice and professional development plans (organisational development and organisational learning projects) in a publicly funded health care system without first addressing existing educational and management structures. Existing systems are based on educational credits for attendance and emerging accountability frameworks (criteria checklists) for clinical governance. Moving to systems that are less summative and more formative, and based on the philosophies of continual quality improvement, require changes to be made in the relevant support systems in order to achieve policy proposals. 


\section{Background}

We are surrounded by realisations that achieving sustained change is a complex activity [1], both in experimental [2] and service development contexts [3]. It is therefore appropriate that the applied behavioural science of organisational development is being recognised as a valid framework to improve the quality of health care services [4] (for definition see Box 1)[5]. Nevertheless, it is difficult to engage organisations in these initiatives, particularly where there is a tradition of autonomy and resistance to external management accountability $[6,7]$. General practice based primary health care in the NHS is a prime example, where general practitioners are, in the main, owner-occupier partnerships, with variable levels of collaboration with other professions such as community nurses, midwives and others. The question of how best to develop general practice organisations remains largely unexplored. The aim of this paper is to discuss previous approaches, summarise the evidence about how to implement up to date and effective practice and to delineate the lessons learnt from a feasibility study of 'practice and professional development plans' [8].

\section{Box I What is organisational development?}

Organisational development is an 'effort [that is] planned, organisation-wide, managed from the top to increase organisational effectiveness and health through planned interventions in the organisation's processes using behavioural science knowledge'[5]. Organisational development includes changes in decision making process, shape and nature of groups, work procedures, job descriptions and roles. The imperative is to change, in order to improve quality and effectiveness, but the management of this process is not a 'neat sequential process'. It typically involves a dynamic complex interaction between those who are wedded to the present state, despite frustrations, and those who share a vision of a future better state. Collaboration and movement are more likely to happen if the vision is shared and congruent with the organisation's existing cultural and political forces [9].

\section{Results}

\section{Previous approaches to practice development}

Many general practices are shining examples of effective organisations: they have professionals that communicate well with patients and with each other and document that they do so; they provide the full range of services which can be reasonably and safely delivered in a community setting; they use modern information technology to record their activity enabling them to achieve almost paperless internal systems. Many practices are also harnessing the information revolution offered by the World Wide Web to support decision making processes between clinicians and patients. All these developments have been achieved in the last 50 years but they are not widely or evenly distributed. Many practices have archaic systems and there is no standard method of determining the level of organisational development achieved across different areas. Examples of low clinical standards and poor interprofessional collaboration are widespread, particularly in deprived socio-economic areas, which serve to reinforce Tudor Hart's inverse care law [10]. As clinical governance systems start to bite, it is becoming clear that existing systems cannot support sustained efforts of organisational development. The converse is in fact true: there are many barriers in place that make it difficult for health authorities to improve quality in primary care [6].

The number of professionals involved in primary care expanded as a new range of services encompassed preventative and predictive areas (e.g. immunisations and cervical screenings). As the complexity increased, it also became necessary to ensure that the services developed were of acceptable quality. Three broad threads can be discerned in the literature: and listed in approximate, if overlapping, chronological order, they are continuing education (1960s onwards), the promotion of teamwork (late 1970s onwards) and more recently, the development of quality and evidence based health care. It is instructive to trace these frameworks and the effect they have had on general practice.

The educational system for general practice has been largely based on a uniprofessional didactic model and incentivised from 1990 onwards in the UK by the award of attendance credits. This paradigm uses the assumption of the individual professional as the provider of patient services and works on the premise that attendance at educational events is a sufficient mechanism to ensure high quality services. Although many aspects of these assumptions are valid, it is also important to note that health care is now a shared activity among many different professionals and that passive attendance is the least effective way of modifying practice. Stanton and Grant examined the educational literature [11] and their conclusions resonate with other reviews showing that interventions involving active participation in workplace settings are more likely to lead to behaviour and organisational change $[12,13]$. These conclusions contributed to the recommendations (not yet implemented) of the Chief Medical Officer's review of continuing professional development in 1998 [14] that educational inputs should be organised within multi-professional organisational contexts - practice and professional development plans (PPDPs) were specified as the suggested mechanism.

The second framework, clearly discernible over the last twenty years or so is the interest in promoting teamwork in primary care. Marsh [15] provides a starting point for this literature advocating the delegation of tasks to oth- 
ers within the 'team' and broadening the roles of clerical, managerial and nursing colleagues, a consistently held and influential view [16]. Jones described pioneering team development work in Oxford and Yorkshire using practice facilitators [17], and Hasler described the 'contractual farces' that have impeded organisational cohesion [18]. Stott sounded a note of caution about the growth of the primary care organisation and argued in favour of a 'core' team, sensing an emerging lack of continuity and fragmentation [19]. West [20], and Øvretveit [21] described the inherent barriers to teamwork in primary care, such as the lack of shared records, accommodation and accountability systems, and suggested changes that could reduce or remove these obstacles. Investments were made in team development initiatives [22] and instruments developed to measure team climate and levels of interprofessional collaboration [23]. But as the organisation became more complex, voices were heard questioning the use of the term team for this increasingly diverse collection of professionals [24] and the wisdom of introducing what Hunter called 'managerialism' into this unstructured context [25].

The third framework is based on the closely related themes of evidence based medicine and quality $[26,27,28]$. The realisation that there are large variations of clinical performance, far beyond the variation attributable to patient factors, has led to the interest in standardisation based on the best available evidence [29], distributed as widely as possible [30]. But the distribution of guidelines had little effect: empirical work demonstrated that passive dissemination was an ineffective method of changing practice [31]. A series of reviews have consistently revealed that there is no single best method to get evidence into practice, and like the reviews of educational interventions, it turns out that there are no 'magic bullets' to be fired at clinical providers or their organisations in the hope that change will automatically follow [32,33,34,35]. Passive approaches (mailings of educational material and didactic educational events) have been shown to be ineffective. The more useful interventions include educational outreach visits, reminders in clinical records (manual or computerised), interactive educational meetings, participation in audit with feedback, local consensus processes and "multifaceted interventions" that include at least two of the above methods [36]. But, as is so often the case, these conclusions are based on limited evidence where there are few studies of different interventions compared against each other and no controlled studies that have evaluated system-wide approaches to organisational development.

However, in spite of the efforts to educate, promote teamwork and pump evidence into practices, there is an increasing understanding that it is not events that bring about change but processes that allow the work of many to be coordinated and summated. Managerial processes (re-engineering, process re-design) are influencing educational interventions and hybrids are emerging, illustrated by the interest in learning organisations [37], of which PPDPs are an example. When considered alongside the arrival of tighter accountability frameworks $[4,38,39]$, the proposal to base practice development on a combination of organisational development and selfdirected learning methods seems to be timely.

Added to the understanding that effective change needs to be a collaborative process across whole systems [40] is the realisation in primary care of the importance of integrating community based professionals [41]. Engaging local agencies can also lead towards the development of community orientated primary care [42], and although this paper focuses on how to develop general practice organisations, there are many opportunities to work with community stakeholders in order to build partnerships between the providers and the consumers of the service [43].

\section{What are practice and professional development plans?}

Practice and professional development plans describe a whole systems-based approach to the development of general practice organisations and reflect the understanding that achieving change relies on arriving at a joint understanding of overall aims. In addition, they also seem to encapsulate the goal of documenting the continuing professional development of individuals, as experienced in the setting of a multidisciplinary group $[8,44]$, but there is a lack of specific detail on this area. The Chief Medical Officer's report suggests that PPDPs focus on the identification of individual and practice needs, although no specific mechanisms are advocated to achieve this difficult and often neglected task. Although there have been no further statutory announcements, a feasibility study was organised in Wales (funded by the then Welsh Office) to test the feasibility of using these proposed 'plans' as vehicles for both practice and professional development.

\section{The PPDP feasibility study}

The study was designed to evaluate the implementation of PPDPs in 22 practices in Wales, funded by the Welsh Office (1998), planned by the Department of Postgraduate Education for General Practice, University of Wales College of Medicine, implemented by the five health authorities in Wales (who appointed PPDP coordinators) and facilitated by four organisations (3 commercial companies and one NHS management unit, namely NHS Staff College Wales). Details of the evaluation have been published separately $[45,46]$ and a summary of the process is provided. It was stipulated by the Welsh Office that each Local Health Group in Wales should be represented by a practice participating in the PPDP process. The 
project was advertised and applications sought. Selected practices were expected to work as a multidisciplinary group with an external facilitator to prioritise one aspect of the organisation that required further development. This would form the task for the development plan; it was suggested that individual contributions to the work could be documented in personal learning portfolios. A budget of $£ 7,500$ per participating practice was nominally allocated to each Health Authority. Each practice would participate in a series of multidisciplinary PPDP workshops (minimum 4). The final outcome was the production of a practice development plan and a set of personal portfolios. This paper describes the experience of the Staff College who facilitated 12 of the total of 18 participating general practices in Wales and the lessons from the exercise are presented to guide future proposals that aim to support organisational development in primary care.

Table I: Budgetary Control of PPDPs

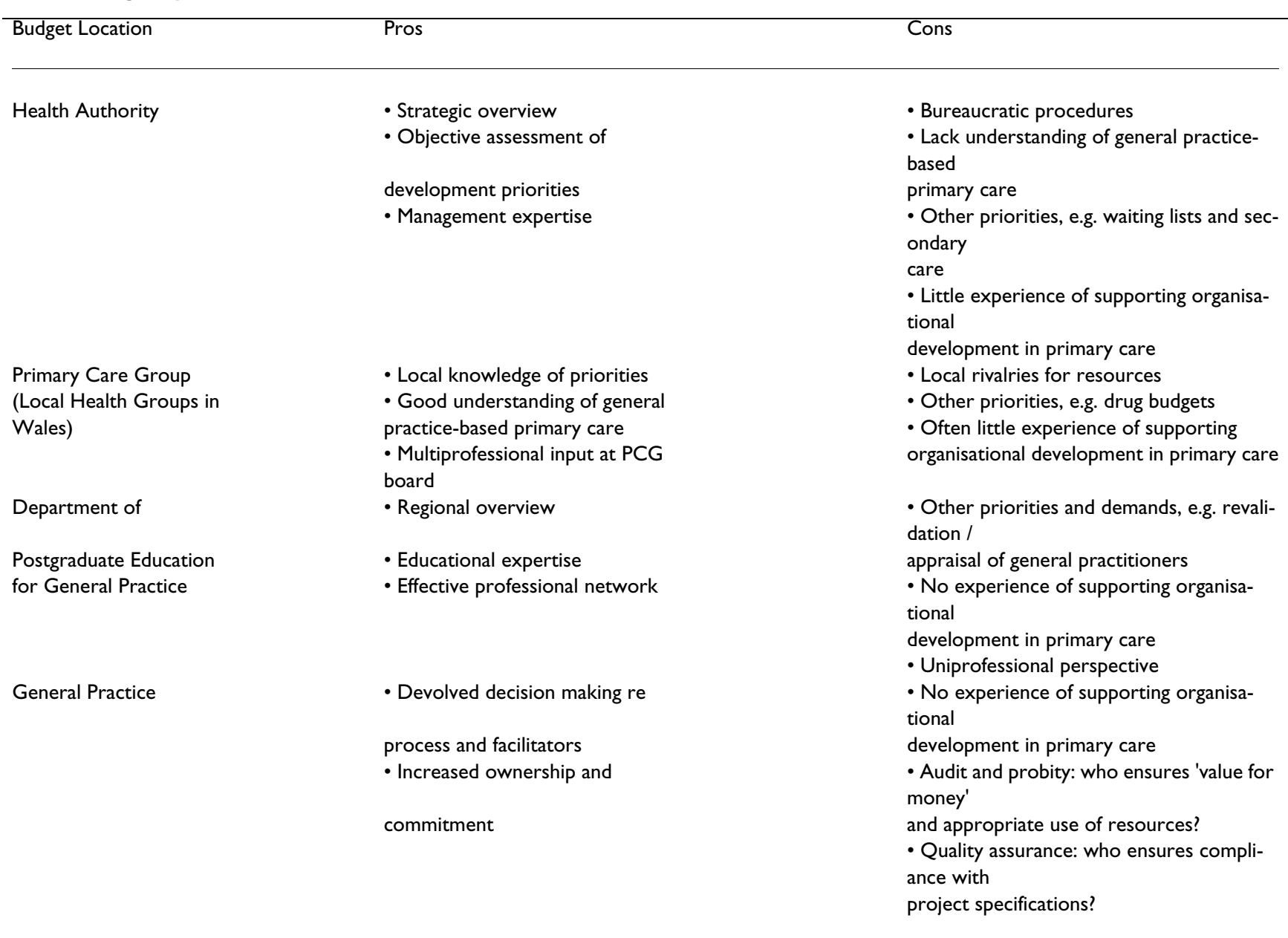

\section{The lessons learnt}

Although the Staff College had previous experience in this field, the PPDP feasibility study provided opportunities to extend its role in primary care development. In order to refine the design of the PPDP process, a series of meetings were held to document the lessons that had been learnt during the planning and facilitation stages. To distill the experience the PPDP documents (project initiation specification, facilitator, practice, selection and project evaluation criteria, workshop minutes and eventual development plans) were analysed and discussed. By a process of debate, reflection and participation in peer reviewed publications we feel able to propose a framework that could act as a template for best practice for supporting organisational development in primary care. 


\section{Education or management?}

The PPDP feasibility study was funded from a regional budget nominated for continuing professional development and planned by a postgraduate education department. However, the health authorities were given the budgets and the task of managing the project. This division illustrates exactly the inherent tension in this area. Is organisational development in general practice an educational or management process? It is of course a combination of both, but unless there is agreement about the origin of budgets to support this work, and clarity about whether the accountability for PPDPs (or equivalent) lies in the sphere of education or management then any future projects are likely to be thwarted. Table 1 outlines the pros and cons of locating PPDP budgets at differing locations in the NHS.

Although only one of the 18 participating practices chose to undertake the PPDP process without the assistance of an external facilitator, this could change if PPDPs become a recognised method of obtaining organisational accreditation and individual revalidation. The costs of replacing staff time (clinical and administrative) are the most obvious early obstacle to PPDPs and it is unlikely, under current contractual arrangements, that practices will hold collaborative multidisciplinary workshops in work time unless some of the opportunity costs are met, at least to some extent. It has been suggested that practices should have half days dedicated to organisational and staff development but funding streams are unclear. Some practices stated that, given a budget, they would prefer to organise their own PPDP without external facilitation. Although this would gain the advantages of securing an increased level of ownership and motivation, two issues would need to be addressed:

1 External facilitation brings many important elements to organisational development. Adherence to effective group dynamics is difficult when members have existing professional hierarchies, e.g. employer-employee contracts. In addition to bringing in the experience of conducting system-wide organisational change, effective external facilitation allows issues to be raised that internal group members would find impossible. Reflections on group process, e.g. the clarification of leadership styles, non-participation and negative contributions, can only be achieved by an external observer who has effective facilitation skills. It is difficult to see how PPDPs can be conducted to a high enough quality without this approach.

2 The second issue is one of financial probity. Although it was noted that direct practice costs were approximately $£ 5000$ (1999 prices), it is going to be vital to ensure that PPDP resources are used appropriately Away days and workshops are expensive exercises, and those who are funding PPDPs need to be satisfied that value for money is being achieved. Perhaps an external facilitator can act as an escrow arrangement, a trusted third party that ensures that both the budget holder and the practice adhere to their financial commitments.

The roles and relationships between the three parties (funder/managers, practices and facilitators) are critical issues. Facilitators are valued by practices for their perceived neutrality and independence, and the external dimension they can bring to internal group dynamics. NHS managers (and by association, sponsors or distant educationalists) are prone to be viewed with more scepticism. Future work needs to acknowledge this tension between perceived accountability to management-led agendas and more open formative interest in organisation development that seeks to add value to the practice effort.

\section{Doing things differently?}

Managing a process of organisational development in general practice is a task that requires expertise in project management, budgetary control and an understanding of the educational systems in place for each primary care professional. If PPDPs are to be supported financially, there will need to be clarity about the remit of each party to ensure effectiveness and probity. Table 2 suggests a possible division of operational responsibilities. Managers of PPDPs (or their equivalent) need to devote as much time to preparing and selecting practices as they give to monitoring progress: ensuring sustained organisational motivation to engage in the time-consuming learning involved in this area is a key ingredient for success. Practices will want to know exactly how to access resources and details about legitimate claims. Facilitators will need a contracted service specification and the supporting agency (Primary Care Group or Health Authority or equivalent) will want reassurances that progress is being achieved against stated goals. Independent end of project evaluation may not be achievable if PPDPs become the established mechanism for service development across all practices but a feasible, dependable monitoring system will need to be established.

\section{Table 2: Operational Responsibility}

\begin{tabular}{ll}
\hline PPDP Manager & Tasks \\
& - Marketing \\
& - Practice Selection \\
& - Facilitator Matching \\
& - PPD montracting \\
& - Budget management \\
Tasks \\
Practice & - Volunteering to participate \\
& - Engaging in selection of facilitator \\
&
\end{tabular}


Table 2: Operational Responsibility

\begin{tabular}{ll}
\hline & - Completing PPDP budgetary claims \\
- Completing an effective organisational change \\
- Allowing inspection and validation \\
PPDP Facilitation
\end{tabular}

\section{Increasing motivation using stepwise recruitment}

The Welsh Office (1998) wanted to make sure that the newly formed LHGs were aware of the PPDP study and stated that each should have a participating practice. The project was therefore promoted to all practices, regardless of their organisational maturity. This requirement caused difficulty. The pressure to arrive at practices that represented geographical areas was a problem: some were persuaded to apply. The short time scales of the study also meant that there was no opportunity to visit applicants, to explain the PPDP concept in enough detail so that an informed decision could be made about their willingness to participate.

It became clear that time invested in making sure that interested practices fully understood the commitment required of them within the PPDP process paid dividends. The feasibility study demonstrated that general practices do not appreciate the paradigm shift represented by the PPDP process. It is therefore vital that initial postal information and explanatory visits should give clear and consistent messages about the shift away from passive learning to learning by 'doing, changing, involving and empowering', and in a more inclusive way than many at first realise. Although the costs seem high, professionals need to appreciate the potential long-term gains. Box 2 lists the steps of an ideal recruitment process.

\section{Box 2 Stepwise practice recruitment}

1 General invitation: all practices could be alerted to organisational development opportunities and invited to respond with an expression of interest signed by key stakeholders.

2 Initial screening process: there could for instance be a policy of providing assistance to practices deemed by various criteria to require targeted assistance (e.g. low performance indicator scores or high levels of staff turnover).

3 Practice briefing: practices are asked to nominate a date for an explanatory meeting. The aim of this would be to gauge the ability of the practice to arrange a multidisciplinary event in which the commitment of the group would be assessed.

4 Confirmed acceptance: the practice confirms with the PPDP management organisation (Primary Care Group or equivalent) that it is willing to participate, and follow the arrangements stipulated in the briefing. This step ensures that acceptance into the process is an informed and positive achievement in its own right.

5 Facilitator selection: this step depends on the arrangements made for approval or provision of units that have the ability to undertake this work.

6 PPDP agreement: an agreement is made with the practice and a contract agreed with the PPDP facilitator, based on regional arrangements.

\section{The facilitation process}

It is important that organisations such as general practice that are not often privy to change management techniques have positive experiences during a PPDP process. The quality of the external facilitation, therefore, becomes a critical factor. The facilitator needs to be able to win confidence that the gains will be worth the effort and cost. As a minimum, facilitators need to be skilled at handling groups $[47,48]$, conversant with organisational learning theory and practice $[49,50]$ and if feasible, be able to support professionals to undertaking self-directed learning portfolios $[49,50]$. They also need to be up to date with NHS policies, particularly with those that stem from National Service Frameworks in order to design relevant and appropriate care pathways [51]. A working knowledge of the roles of professionals in primary care may be helpful but not essential - many working practices are more easily challenged if facilitators have an openminded inquisitiveness about existing work patterns. Above all the PPDP process needs to be one that allows time to assess, plan, review and re-assess in iterative cycles. Figure 1 provides an outline of a typical PPDP process.

\section{Process Problems}

All organisations have formal and informal hierarchies and problems related to conflicts about power, status, inclusion and exclusion in decision making processes. In many situations these hierarchies, based on politics, experience, skills and qualifications are not open to challenge. There are, however, instances where structures stifle useful contributions and it is the facilitator's role to generate open and creative communication channels.

Continuing professional development is being actively promoted within the NHS, based primarily on self-di- 


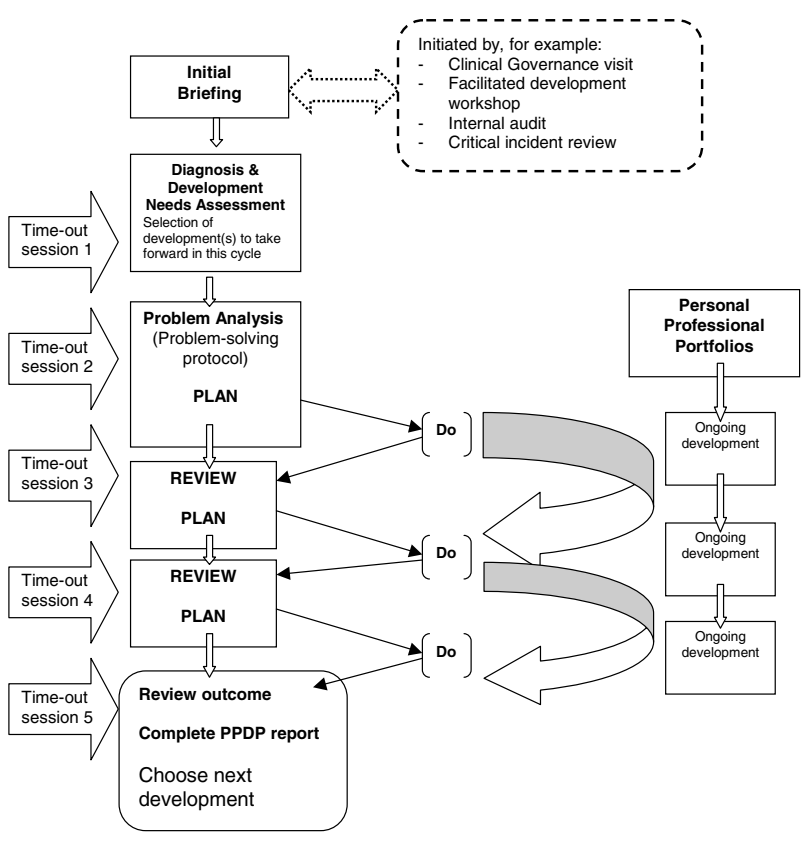

Figure I

The Practice Professional Development Plan

rected and problem-based learning approaches to education. For professionals who have only previously experienced didactic teaching these are novel methods. They may be resisted and even associated with degrees of anxiety as they seem, ironically, to be linked to the introduction of formal assessments such as revalidation [52]. Given this context, it is hardly surprising to find that it is difficult to introduce organisational development plans that also expect individuals to complete personal portfolios. Facilitators may well be left asking if the priority is to deliver an effective organisational change or to produce a set of learning portfolios. It may be too much to expect both processes to be given equal weight.

The feasibility study demonstrated the benefit of having PPDP 'templates' which allowed the practice to record the discussions, action points and progress over time in a structured format. This minimised the need to write reports outside the workshops yet ensured that the participants took the responsibility of clearly documenting the tasks each individual had to complete by the next workshop and efficiently generated a permanent record of the PPDP process.

\section{Discussion}

PPDPs cannot be introduced into primary care until investments have been made in a wide range of support structures, preferably in units that can be perceived as having long-term interests in non-profit public service organisational development that enhances the quality of patient services. The exact size and location of such units should reflect regional contexts but they should retain enough capacity to ensure a critical mass of sustained experience in this area. If financial support is to be provided to practices, there needs to be clarity about the revenue source; specifically whether the money comes from service development or educational budgets. If it is to be an educational pot, are all disciplines who work in general practice organisations going to contribute? If this fundamental issue is ever solved there will then need to be transparency about the range of legitimate expenses. Whatever financial support is provided, PPDPs will also need a cadre of health service managers and educators who fully understand the concept of linking individual learning to organisational development and appreciate the importance of engaging the expertise of neutral facilitators who can challenge assumptions. Neither the existing primary care support structures in the NHS (fragmented and disparate after health authorities took over the functions of the Family Health Services Authorities) nor the uniprofessional departments of postgraduate education have the necessary breadth of experience to introduce this paradigm shift across primary care.

General practice is rooted in an independent contractor service, although the Primary Care Act (1997) has allowed many regions to explore the possibilities of a salaried employment option [53]. Although regarded by some as a restrictive contract, many general practitioners have demonstrated enormous creativity and motivation. Others, however, have been unwilling to invest in new structures or expand their own roles, or those of their managerial and nursing colleagues. NHS managers have been unable to ensure uniform standards of service access or quality. Although the small business mentality of general practice undoubtedly leads to effective use of resources - inefficiencies are reflected in lowered profits - this attitude can also limit investment in both buildings and staff. Perversely, this often happens in the most deprived socio-economic areas where the competition for patients is limited. By having high lists and minimal overheads general practitioners in such areas earn high incomes and have no interest in developing collaborative teams that would restrict their autonomy. Introducing PPDPs without first of all addressing these structural issues would lead to even further polarisation of quality in primary care organisations.

We have come to realise that organisational development in general practice will only flourish when a support system is created, composed of clearly allocated budgets, experienced facilitators and a sustainable contractual framework for general practice, which has incor- 
porated both clinical governance concerns and the shifting management structures within primary care (Primary Care Groups and Trusts). The feasibility study also revealed two other lessons. PPDPs are the start of a process: practices should ideally use the process as their chance to learn how to learn, to embrace the organisational learning model and establish an approach that can be replicated for future challenges. The second lesson, and perhaps the most fundamental lesson of all: PPDPs worked best where there was effective leadership within the organisation that had been able to convey the importance and relevance of the project. As the pressure to standardise services increases, general practice partnerships (the current model for most general practice partnerships) will have to be much clearer about designating leadership positions and allowing open debate about strategic organisational development.

\section{Acknowledgements}

Our thanks go to the National Assembly for funding the PPDP feasibility study, Sandra Carlisle for evaluating the initiative and to Simon Smail at the Department of Postgraduate Education for his support. We are grateful to Sharon Caple for her meticulous attention to detail at all stages of the work.

\section{References}

I. Cilliers P: Complexity and postmodernism: understanding complex systems. London: Routledge, 1998,

2. Campbell M, Fitzpatrick R, Haines A, Kinmonth AL, Sandercock P, Spiegelhalter $D$, et al: Framework for design and evaluation of complex interventions to improve health. BMJ 2000, 32 I (7262):694-696

3. Koek C: Time for organisational development in healthcare organisations. BMJ I 998, 3 I 7:| 267-8

4. Huntington J, Gillam S, Rosen R: Clinical governance in primary care: Organisational development for clinical governance. BMJ 2000, 32 I (7262):679-682

5. Beckhard R: Organisational development: strategies and models. Reading MA: Addison Wesley, 1969.

6. Marshall $\mathrm{MN}$ : Improving quality in primary care: qualitative case study of barriers faced by health authorities. BM] 1999, 3 19:164-7

7. Rogers S, Humphrey C, Nazareth I, Lister S, Tomlin Z, Haines A: Designing trials of interventions to change professional practice in primary care: lessons from an exploratory study of two change strategies. $B M J$ 2000, 320:1580-3

8. Carlisle S, Elwyn G, Smail SA: Personal and practice development plans in primary care in Wales. Journal of Interprofessional Care 2000, 14:39-48

9. Senge PM: The Fifth Discipline: The Art and Practice of the Learning Organisation. Century Books: London, 1994,

10. Hart JT: The inverse care law. The Lancet 1991, I:405-12

II. Stanton F, Grant J: The effectiveness of continuing professional development. London: Joint Centre for Medical Education, Open University, 1997,

12. Davis DA, Thomson MA, Oxman AD, Haynes RB: Evidence for the effectiveness of CME. A review of 50 randomized controlled trials. JAMA 1992, 268: I III-7

13. Davis DA, Thomson MA, Oxman AD, Haynes RB: Changing physician performance. A systematic review of the effect of continuing medical education strategies. JAMA I995, 274:700-5

14. Department of Health. A review of continuing professional development in practice: a report by the Chief Medical Officer. London DoH 1998, [http://open.gov.uk/doh/cmo/cmoh.htm]

15. Marsh GN, Kaim-Caudle P: Team care in general practice. London: Croon Helm, 1976,

16. Marsh GN: Caring for larger lists. BMJ 1991, 303:1312-6

17. Jones RVH: Getting better: education and the primary health care team. BMJ 1992, 305:506-8

18. Hasler J: The primary health care team. BMJ 1992, 305:232-4
19. Stott $\mathrm{NCH}$ : When something is good, more of the same is not always better. BJGP 1993, 43:254-7

20. West M, Field R: Teamwork in primary care I. Perspectives from organisational psychology. Journal of Inter-professional Care 1994, 9:1 17-122

21. Øvretveit J: Coordinating community care. Open University Press: Milton Keynes, 1993

22. Pritchard P, Pritchard J: Teamwork for primary and shared care: a practical workbook. 2 ed. Oxford: Oxford Medical Publications, 1994,

23. Anderson NR, West M: The team climate inventory: manual and users' guide. Windsor: ASE Press, 1994,

24. Pearson P: The primary health care non-team? BM] 1994 309:1387-1388

25. Hunter DJ: The changing roles of health personnel in health and health care management. Soc Sci Med 1996, 43:799-808

26. Sackett DL, Rosenberg WMC, Muir Gray JA, Haynes RB, Richardson WS: Evidence based medicine: what it is and what it isn't. BMJ |996, 3 | 2:7|-2

27. Department of Health. A First Class Service; Quality in the NHS. London Department of Health, 1998, [http:// www.open.gov.uk/doh/newnhs/quality.htm]

28. McColl A, Roderick P, Gabbay J, Smith H, Moore M: Performance indicators for primary care groups: an evidence based approach. BMJ 1998, 3 I 7(7 I 69): I354-1360

29. Sackett D, Scott Richardson W, Rosenberg W, Haynes RB: Evidence Based Medicine. How to practice and teach EBM. New York: Churchill Livingstone, 1997,

30. NHS Centre for Reviews and Disseminations. Implementing clinical practice guidelines: can guidelines be used to improve clinical practice? |994, 8:

31. Grimshaw JM, Russell IT: Effect of clinical guidelines on medical practice: a systematic review of rigorous evaluations. Lancet 1993, 342:1317-1322

32. Oxman AD, Thomson MA, Davis DA, Haynes RB: No magic bullets: a systematic review of 102 trials of interventions to help health care professionals deliver services more effectively or efficiently. Can Med Assoc J 1995, I 53:|423-31

33. Bero LA, Grilli R, Grimshaw JM, Harvey E, Oxman AD, Thomson MA: Getting research findings into practice: Closing the gap between research and practice: an overview of systematic reviews of interventions to promote the implementation of research findings. $B M / 1998,3$ I 7(7 I 56):465-468

34. Wensing $M$, van der Weijden T, Grol R: Implementing guidelines and innovations in general practice: which interventions are effective. The British Journal of General Practice 1998, 48:99|-7

35. NHS Centre for Reviews and Dissemination. Getting Evidence into Practice. York: The University of York, 1999,

36. Eve R, Golton I, Hodgkin P, Munro J, Musson G: Learning from FACTS: lessons from the framework for appropriate care throughout Sheffield projects. Occasional Paper No. 97/3. Sheffield: School of Health and Related Research ScHARR, 1997,

37. Easterby-Smith M, Burgoyne J, Araujo L: Organizational learning and the learning organization. London: Sage, 1999,

38. Garside P: Organisational context for quality: lessons from the fields of organisational development and change management. Quality in Health Care 1998, 7 Supplement:S8-I5

39. Moss M, Garside P, Dawson S: Organisational change: the key to quality improvement. Quality in Health Care 1998, 7 Supplement:SI-2

40. Pratt J, Plamping D, Gordon P: Working whole systems. London: King's Fund, 1999,

4I. Elwyn G, Smail J: Integrated Teams in Primary Care. Oxford: Radcliffe Press, 1998 ,

42. Pollock A, Majeed F: Community orientated primary care. BMJ 1995, 3 1 0:48|-2

43. Plamping D, Gordon P, Pratt J: Modernising the NHS: Practical partnerships for health and local authorities. BMJ 2000, 320:1723-1725

44. Elwyn G: Professional and practice development plans for primary care. Editorial. BMJ 1998, 3 I 6:1619-20

45. Elwyn G, Smail SA, Carlisle S: Practice and Professional Development Plans in Primary Care: a feasibility study in the five health authorities in Wales: Report to the National Assembly of Wales. Cardiff: Department of Postgraduate Education for General Practice in Wales, University of Wales College of Medicine, 2000. 
46. Elwyn G, Carlisle S, Hocking P, Smail S: Practice and professional development plans (PPDPs): results of a feasibility study. Submitted BMJ 2000,

47. Heron J: The Facilitator's Handbook. London: Kogan Page, 1989,

48. Elwyn G, Greenhalgh T, Macfarlane F, Koppel S: Groups: a guide to small group work in healthcare, management and education. Oxford: Radcliffe Medical Press, 200I.

49. Mathers N, Challis M, Howe A, Field N: Portfolios in continuing medical education - effective and efficient. Medical Education 1999, 33:521-30

50. Parboosingh J: Learning portfolios: potential to assist health professionals with self-directed learning. Journal of Continuing Education in the Health Professions 1996, 16:75-81

51. Middleton S, Roberts A: Integrated Care Pathways. Oxford: ButterworthHeineman, 2000,

52. General Medical Council. Proposals for revalidation. London: General Medical Council, 2000,

53. National Health Service (Primary Care) Act 1997. London: The Stationery Office Limited, 1997,

\section{Pre-publication history}

The pre-publication history for this papercan be accessed here:

http://www.biomedcentral.com/content/backmatter/

1471-2296-1-2-b1.pdf

Publish with BioMedcentral and every
scientist can read your work free of charge

"BioMedcentral will be the most significant development for disseminating the results of biomedical research in our lifetime."

Paul Nurse, Director-General, Imperial Cancer Research Fund

Publish with BMc and your research papers will be:

- available free of charge to the entire biomedical community

- peer reviewed and published immediately upon acceptance

- cited in PubMed and archived on PubMed Central

- yours - you keep the copyright

Submit your manuscript here:

http://www.biomedcentral.com/manuscript/

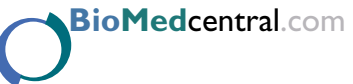

editorial@biomedcentral.com 